\title{
Evaluation of an Organic-Inorganic Hybrid Insulation Material using an Inorganic Filler and Polyurethane with a Foaming Condition
}

\author{
Hyun-Kyung Noh, Hun Song, Yong-Sik Chu, Ji-Sun Park*, and Jong-Kyu Lee ${ }^{\dagger}$ \\ Energy \& Environment Division, Korea Institute of Ceramic Engineering \& Technology, Seoul 153-801, Korea \\ *Building Research Department, Korea Institute of Construction Technology, Goyang 411-712, Korea \\ (Received October 15, 2012; Revised November 16, 2012; Accepted November 20, 2012)

\section{무기질 충진재와 폴리우레탄을 활용한 유·무기 복합 단열소재의 발포조건에 따른 특성 평가 \\ 노현경·송 훈 · 추용식 · 박지선* · 이종규 ${ }^{\dagger}$ \\ 한국세라믹기술원 에너지환경소재본부 \\ *한국건설기술연구원 공공건축연구본부} \\ (2012년 10월 15일 접수 ; 2012년 11월 16일 수정 ; 2012년 11월 20일 채택)
}

\begin{abstract}
In this work, the properties of an organic-inorganic hybrid insulating material using an inorganic filler and polyurethane foam with different foaming conditions were investigated. At weight ratios of polyol and isocyanate of 1 to 1.2 good foaming properties were noted. In addition, an addition of $0.4 \mathrm{~g}$ of water, $0.1 \mathrm{~g}$ of surfactant, and $0.1 \mathrm{~g}$ of catalyst with respect to the composites of polyol at $5 \mathrm{~g}$ and isocyanate at $6 \mathrm{~g}$ showed the lowest apparent density and thermal conductivity. The pore size was smaller in the organic -inorganic hybrid foaming body with an increase in the $\mathrm{CaCO}_{3}$ addition amount. Moreover, the apparent density and thermal conductivity were increased when the added amount of $\mathrm{CaCO}_{3}$ increased. Increasing the amount of $\mathrm{CaCO}_{3}$ powder is expected to improve the flame retardant capabilities; however, doing this tends to increase the apparent density and thermal conductivity.
\end{abstract}

Key words : Hybrid insulation, $\mathrm{CaCO}_{3}$, Foaming condition, Thermal conductivity, Apparent density

\section{1. 서 론}

최근 에너지 효율의 극대화, 이산화탄소 감축 등 친환 경 소재에 대한 관심이 높아지고 있으며, ${ }^{1-3)}$ 따라서 주택 및 산업 부문의 열효율을 향상시키기 위한 관리가 필요 하며, 열 손실을 최소화하기 위해 효율적인 열관리 시스 템 구축뿐만 아니라, 근본적으로 열 손실을 최소화 할 수 있는 저열전도성 소재 개발이 필요다. 이를 위해서는 건 물분야에서는 친환경/에너지효율 극대화된 신개념의 단열 소재 개발이 절실히 필요하다. ${ }^{4-6)}$ 기존 단열재 중 유기단 열재의 경우 단열성능이 우수하고 시공성이 좋기 때문에 널리 사용되고 있으나 화재발생시 단열소재 자체가 연소 하여 화재가 급속히 확대되는 등 내화성능 면에서 크게 취약하고, 특히 연소 시 발생되는 유독가스는 인체에 치 명적으로 작용한다. ${ }^{7-9)}$ 반면에 무기단열재의 경우 유기단

${ }^{\dagger}$ Corresponding author : Jong-Kyu Lee

E-mail : ljk25@kicet.re.kr

Tel : +82-2-3282-2422 Fax : +82-2-3282-2430
열재에 비해 화재에 강한 내화특성은 우수하나 상대적으 로 중량이 무겁고 시공성이 떨어지며 또한 단열재 고유 기능인 단열성능이 떨어지는 단점이 있다. ${ }^{10,11)}$ 또한 무 기계 단열재인 그라스울이나 락울 등은 섬유상의 형태로 인해 제작 및 시공과정에서 분진이 발생되며 이에 대한 대응책으로 섬유의 길이를 길게 하여 인체 침투에 대한 위협을 방지하고 있으나 전적으로 인체 유해성 논란에서 자유롭지 못한 실정이다. 현재 공동주택 등 건축물의 단 열 성능 요건이 점점 더 강화되고 있는 실정이며 무기계 단열재의 경우 상대적으로 단열성이 취약하여 유기단열 재 보다 중량이 더 무거움에도 불구하고 단열재의 두께 가 더 두꺼워져야 하는 치명적인 문제점을 안고 있다.

따라서 유기계 및 무기계 단열재 각각의 문제점을 해 결하기 위해 다양한 노력이 시도되고 있으며, 유기 단열 소재의 난연화 기술과 무기단열소재의 단열성능 향상 및 경량성 확보를 위한 연구가 진행 중에 있다. ${ }^{12-14)}$ 또한 최 근 유·무기 복합화를 통한 초경량, 난연성을 가지는 유· 무기 복합 단열소재의 개발에 관심이 집중되고 있다. 
본 연구에서는 대표적인 유기단열소재인 우레탄 소재 에 무기질 충진재로 $\mathrm{CaCO}_{3}$ 를 복합화 하여 발포시킬 때 의 각종 발포조건에 따른 유·무기 복합단열소재의 특성 을 평가하였다.

\section{2. 실험방법}

\section{1. 출발원료}

유·무기 복합단열소재의 유기 바인더 물질로 $\mathrm{S}$ 사의 하 이드록시기 $\left(\mathrm{OH}^{-}\right)$의 활성수소를 가지는 폴리올(상품명 : $\mathrm{TF}-400)$ 과 $(-\mathrm{N}=\mathrm{C}=\mathrm{O})$ 라는 관능기를 가지는 이소시아 네이트(상품명: M-200)을 사용하여 반응시켜 우레탄 결합 을 시키는 고분자 화합물을 기본 물질로 사용하였다. 폴 리우레탄 폼 합성에 영향을 미치는 요소로 미세하고 많 은 기포를 형성시키기 위한 또한 실록산계 계면활성제(상 품명 : B-8462) 및 촉매(DMCHA)(상품명 : $33 \mathrm{LV}$ )를 소량 으로 첨가하였다. 폴리우레탄 반응의 발포제로서 물을 사 용하였다. 무기질 충진재로는 $6.1 \mu \mathrm{m}$ 의 평균입도를 가지 는 $\mathrm{CaCO}_{3}$ 를 사용하였다.

\section{2. 발포체 제조}

유·무기 복합 발포체는 제조를 위하여 먼저 폴리올에 반응촉진제, 유화제 및 발포제로 물을 일정한 비율로 첨 가한 용액에 무기분체를 일정량 첨가하여 혼합한 후 이 소시아네이트를 마지막으로 첨가하여 균일하게 혼합한 후 금속 몰드에 일정량을 혼합조성물을 주입시킨 후 상온에 서 발포를 시켰다. 개략적인 유-무기 복합발포제 제조 공정을 Fig. 1에 나타내었다.

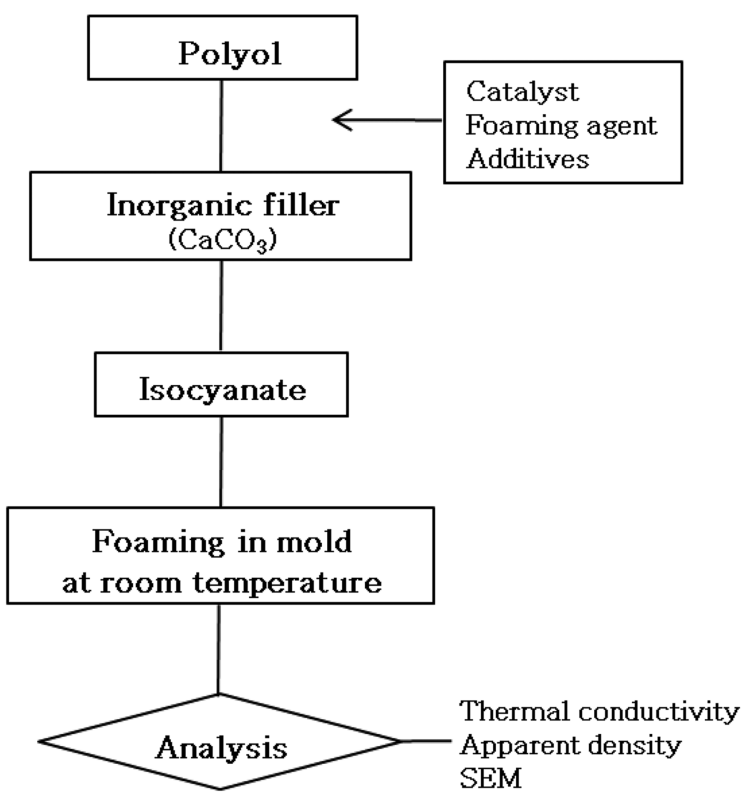

Fig. 1. Experimental procedure of foaming process.

\section{3. 원료 배합 및 분석}

본 연구에 사용된 우레탄 반응의 기본물질인 이소시아 네이트 : 폴리올 : 계면활성제 : 촉매 : 물의 배합비는 $6 \mathrm{~g}$ : $5 \mathrm{~g}: 0.1 \mathrm{~g}: 0.1 \mathrm{~g}: 0.4 \mathrm{~g}$ 을 기준으로 하였다. 무기분체인 $\mathrm{CaCO}_{3}$ 의 첨가량은 상기의 우레탄 반응의 기본물질과 무 게비로 $1: 1$ 로 혼합을 하여 발포시켰다. 이소시아네이트, 폴리올, 계면활성제, 촉매 및 물의 첨가 영향을 알아보기 위하여 각각의 첨가량을 증감 시키면서 발포특성을 평가 하였다. 물성 평가를 통해 최적의 적정 비율을 유추해 낸 후 시편을 제작하였다. 제작한 시편을 $20 \times 20 \times 20 \mathrm{~mm}$ 크 기로 성형 후 겉보기 비중을 측정하였으며, 발포체의 발 포형상은 $\mathrm{SEM}$ 으로 관찰을 하였다. 열전도율 측정은 평 판 열류가압식으로 측정을 하였으며 시료의 크기는 $200 \times$ $200 \times 20 \mathrm{~mm}$ 의 것을 사용하였다.

\section{3. 결과 및 고찰}

\section{1. 폴리올과 이소시아네이트 첨가량에 따른 비중}

발포형성이 기본이 되는 폴리올과 이소시아네이트의 변 화에 따른 특성을 알아보기 위하여 폴리올 $5 \mathrm{~g}$ 계면활성 제 $0.1 \mathrm{~g}$, 촉매 $0.1 \mathrm{~g}$, 그리고 발포제인 물을 $0.4 \mathrm{~g}$ 인 조성 에 대해서 이소시아네이트를 $1.25 \mathrm{~g}, 3 \mathrm{~g}, 6 \mathrm{~g}, 12 \mathrm{~g}$ 첨가하 였을 경우의 겉보기 비중 변화를 Fig. 2에 나타내었다. 이 때 무기분체인 $\mathrm{CaCO}_{3}$ 도 상기의 조성에 대해서 무개비로 $1: 1$ 첨가하였다. 폴리올 $5 \mathrm{~g}$ 에 대해서 이소시아네이트를 $1.5 \mathrm{~g}$ 첨가한 경우의 비중은 $0.2025 \mathrm{~g} / \mathrm{cm}^{3}$ 이었으며 $3 \mathrm{~g}$ 첨가하였을 경우 $0.1285 \mathrm{~g} / \mathrm{cm}^{3}$ 로 낮아졌다. 폴리올 $5 \mathrm{~g}$ 에 대해서 이소시아네이트를 $6 \mathrm{~g}$ 첨가하였을 경우 비중이 $0.0316 \mathrm{~g} / \mathrm{cm}^{3}$ 으로 가장 낮은 값을 보여주고 있다. 폴리올 $5 \mathrm{~g}$ 에 대해서 이소시아네이트 첨가량을 더욱 많이 첨가할 경우 발포가 잘 이루어지지 않아 비중이 증가를 하였다. 본 실험에서는 폴리올과 이소시아네이트의 무게비가 $1: 1.2$ 일 경우 발포특성이 양호하였으며 비중이 가장 낮았다.

\section{2. 발포제(water) 함량에 따른 특성}

발포제인 물의 함량에 따른 특성변화를 알아보기 위하 여 폴리올 $5 \mathrm{~g}$, 이소시아네이트 $6 \mathrm{~g}$, 계면활성제 $0.1 \mathrm{~g}$, 촉 매 $0.1 \mathrm{~g}$ 의 조성에 대해서 물을 $0.1 \sim 0.8 \mathrm{~g}$ 첨가하였을 경 우의 겉보기 비중과 열전도율 변화를 Fig. 3에 나타내었 다. 물의 함량이 적으면 발포가 불량하여 비중이 높게 나 타났으며 물의 함량이 많을 경우 과다 발포로 기공형성 이 불량하여 다시 비중이 증가하였다. 물의 함량이 $0.4 \mathrm{~g}$ 첨가하였을 경우 발포형상도 좋았고 비중이 가장 낮았다. 또한 열전도율도 비중변화가 비슷한 경향을 보이고 있으며, 물의 함량이 증가함에 따라 열전도율도 낮아졌으며 물의 함량이 $0.4 \mathrm{~g}$ 첨가하였을 때의 열전도율은 $0.02891 \mathrm{kcal} / \mathrm{mh}^{\circ} \mathrm{C}$ 로 가장 낮게 나타났다. 물을 $0.4 \mathrm{~g}$ 이상 첨가하였을 때는 


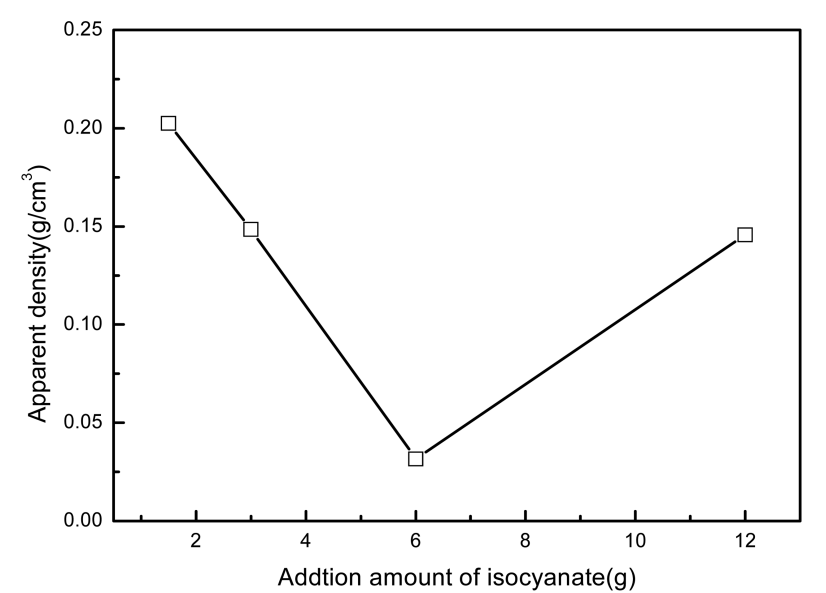

Fig. 2. Change of apparent density with addition amount of isocyanate.

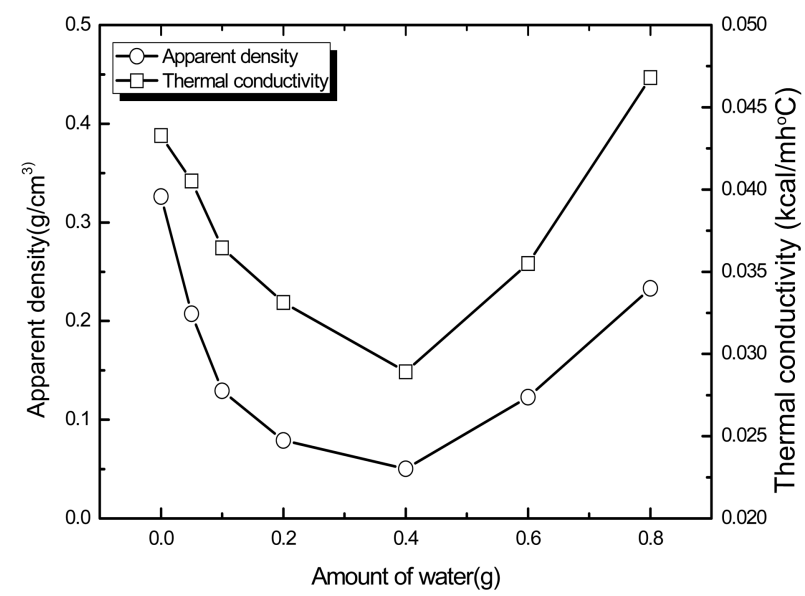

Fig. 3. Changes of apparent density and thermal conductivity with addition amount of water(foaming agent).

열전도율이 다시 증가를 하고 있었다. 따라서 본 실험에 서는 발포제인 물의 함량을 폴리올 $5 \mathrm{~g}$, 이소시아네이트 $6 \mathrm{~g}$, 계면활성제 $0.1 \mathrm{~g}$, 촉매 $0.1 \mathrm{~g}$ 의 조성에 대해서 $0.4 \mathrm{~g}$ 비율로 첨가하였을 때 가장 좋은 결과를 얻었다.

Fig. 4에 발포제인 물을 첨가하지 않은 시료와 발포제 를 $0.4 \mathrm{~g}$ 첨가하였을 때의 SEM 사진을 나타내었다. 물을 첨가하지 않은 시료에서는 발포가 거의 이루어지지 않았 으며 물을 $0.4 \mathrm{~g}$ 첨가한 시료에서 약 $200 \mu \mathrm{m}$ 정도의 기공 분포를 가지는 균일한 발포체를 얻을 수 있었다.

\section{3. 계면활성제 및 촉매 첨가에 따른 특성}

일반적으로 계면활성제를 첨가하여 표면장력을 낮추어 서 기공형성 및 셀을 안정화시킨다. 본 실험에서는 폴리 올 $5 \mathrm{~g}$, 이소시아네이트 $6 \mathrm{~g}$, 촉매 $0.1 \mathrm{~g}$, 물 $0.4 \mathrm{~g}$ 에 대해서 실록산계 계면활성제를 조성에 대해서 $0.1 \sim 0.8 \mathrm{~g}$ 첨가하 였을 때의 겉보기 비중과 열전도율 변화를 Fig. 5에 나타 내었다. 계면활성제를 첨가하지 않았을 경우에는 기공형
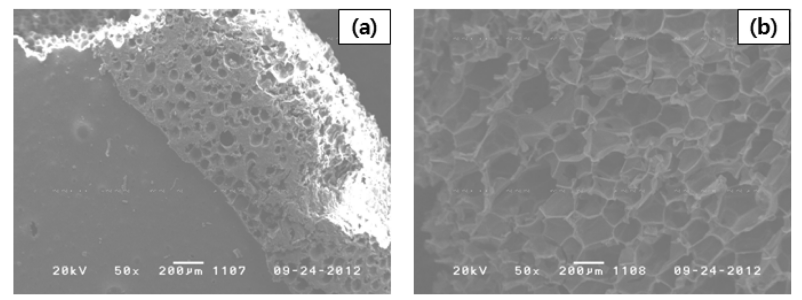

Fig. 4. SEM photographs of foaming body with and without water: (a) no added and (b) water added.

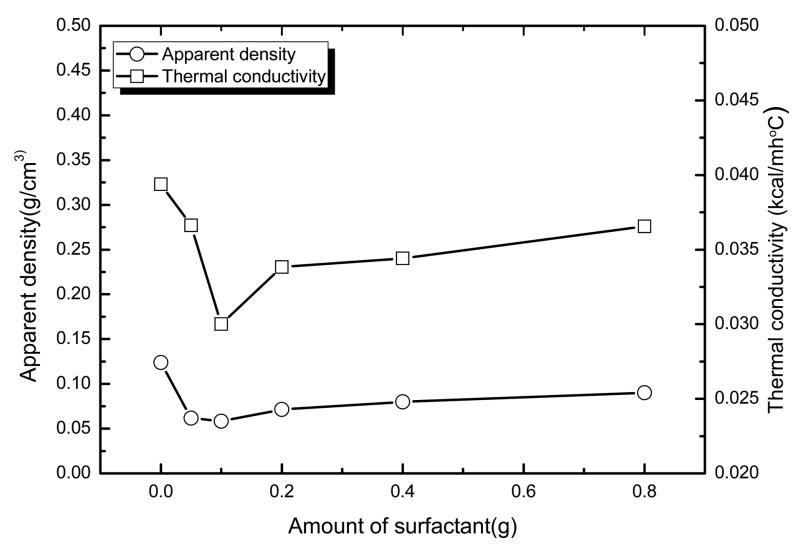

Fig. 5. Changes of apparent density and thermal conductivity with addition amount of surfactant.

성이 좋지 않아 비중이 높게 나타났으며 계면활성제를 첨 가함에 따라 비중이 낮아지고 있음을 알 수 있다. 계면활 성제를 $0,1 \mathrm{~g}$ 첨가하였을 때 가장 낮은 비중을 보이고 있 으며, 첨가량이 증가함에 따라 비중이 약간 증대하고 있 음을 보여주고 있다. 열전도율 변화에서도 계면활성제의 첨가에 따라 열전도율이 낮아지고 있다. 비중의 결과와 비슷하게 $0.1 \mathrm{~g}$ 첨가 시 가장 낮은 열전도율을 보이고 있 으며 첨가량의 증가에 따라 다시 열전도율이 약간 증가 하는 경향을 보이고 있다.

Fig. 6에 계면활성제를 첨가하지 않은 시료와 계면활성 제를 $0.1 \mathrm{~g}$ 첨가하였을 때의 SEM 사진을 나타내었다. 계 면활성제를 첨가하지 않은 시료에서는 발포체의 셀의 안 정성이 떨어져 기공이 부서져 있음을 알 수 있으며 $0.1 \mathrm{~g}$ 의 계면활성제를 첨가한 경우 기공분포가 안정되어 있음 을 알 수 있다.

촉매의 첨가량에 따른 특성변화를 알아보기 위하여 폴 리올 $5 \mathrm{~g}$, 이소시아네이트 $6 \mathrm{~g}$, 계면활성제 $0.1 \mathrm{~g}$, 물 $0.4 \mathrm{~g}$ 의 조성에 대해서 촉매를 $0.1 \sim 0.8 \mathrm{~g}$ 첨가하였을 경우의 겉보 기 비중과 열전도율 변화를 Fig. 7에 나타내었다. 촉매를 첨가함에 따라 발포형성의 반응성이 좋아져서 비중이 낮 아지고 있다. 촉매를 $0.1 \mathrm{~g}$ 첨가하였을 경우 가장 낮은 비 중을 보이고 있으며 첨가량이 증가함에 따라 비중은 약 간 증가하고 있음을 알 수 있다. 촉매 첨가량에 따른 열 전도율 변화에서는 촉매 첨가에 따라 열전도율이 낮아지 


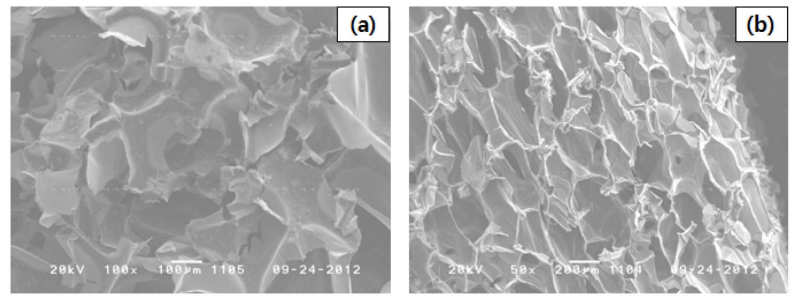

Fig. 6. SEM photographs of foaming body with and without surfactant: (a) No added and (b) surfactant added.

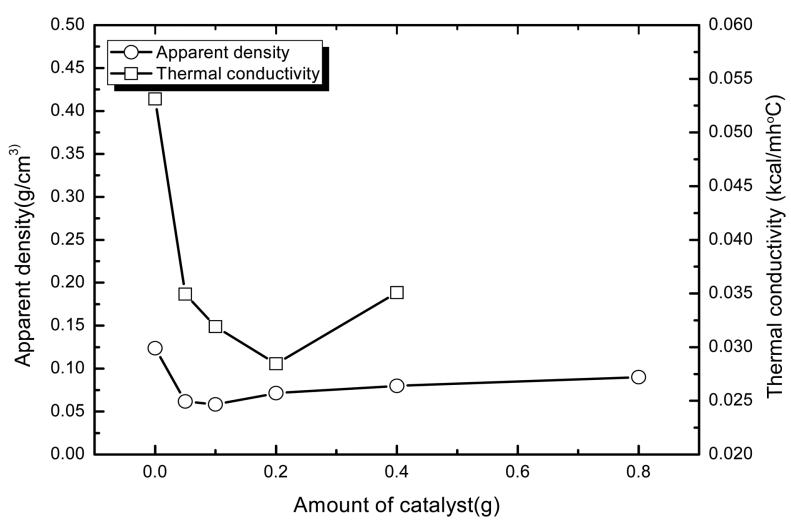

Fig. 7. Changes of apparent density and thermal conductivity ith addition amount of catalyst.

고 있으며 $0.2 \mathrm{~g}$ 을 첨가하였을 경우 $0.2891 \mathrm{kcal} / \mathrm{mh}$ 가장 낮은 값을 보여주고 있다. 촉매의 첨가량을 $0.2 \mathrm{~g}$ 이상으 로 증가시키면 다시 열전도율이 높아 졌으며 $0.4 \mathrm{~g}$ 이상 으로 첨가를 하면 반응이 너무 빨라 발포체 제조가 힘들 었다.

Fig. 8에 촉매를 첨가하지 않은 시료와 계면활성제를 $0.1 \mathrm{~g}$ 첨가하였을 때의 $\mathrm{SEM}$ 사진을 나타내었다. 촉매를 첨가하지 않은 시료에서는 발포체의 기공형성이 불균일 하였으며 $0.1 \mathrm{~g}$ 의 촉매를 첨가한 경우 기공분포가 안정되 어 있음을 알 수 있다.

\section{4. $\mathrm{CaCO}_{3}$ 첨가량에 따른 특성}

$\mathrm{CaCO}_{3}$ 첨가량에 따른 발포특성을 알아보기 위하여 폴 리올 $5 \mathrm{~g}$, 이소시아네이트 $6 \mathrm{~g}$, 계면활성제 $0.1 \mathrm{~g}$ 촉매 $0.1 \mathrm{~g}$, 물 $0.4 \mathrm{~g}$ 의 비율로 구성된 기본 혼합물에 대해서 평균입
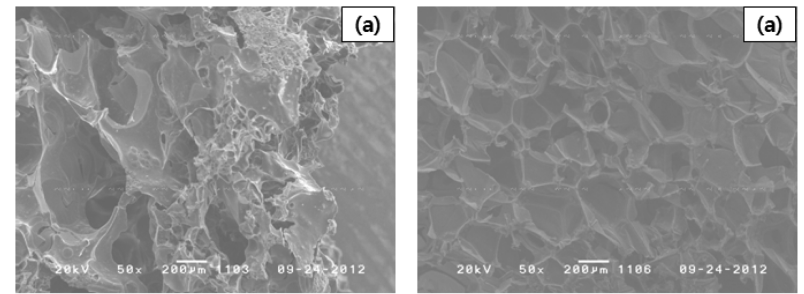

Fig. 8. SEM photographs of foaming body with and without catalyst: (a) No added and (b) surfactant added.

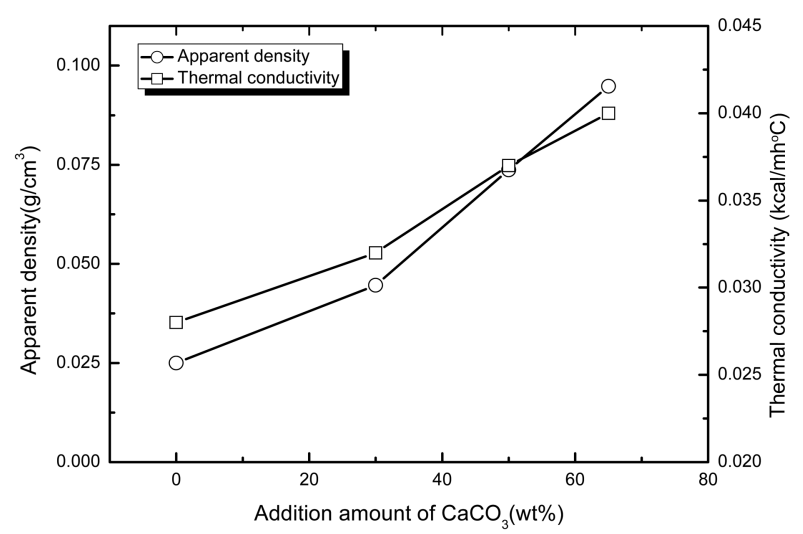

Fig. 9. Changes of apparent density and thermal conductivity with addition amount of $\mathrm{CaCO}_{3}$.

경 약 $6.1 \mu \mathrm{m}$ 의 $\mathrm{CaCO}_{3}$ 를 무게비로 $0 \%, 30 \% 50 \%, 65 \%$ (내 할) 첨가하였을 때의 겉보기 비중과 열전도율 변화를 Fig. 9 에 나타내었다. $\mathrm{CaCO}_{3}$ 를 첨가하지 않았을 경우의 비중은 약 $0.025 \mathrm{~g} / \mathrm{cm}^{3}$ 으로 나타났으나 $\mathrm{CaCO}_{3}$ 의 첨가량이 증가 할수록 비중이 증가하고 있으며 $\mathrm{CaCO}_{3}$ 를 $65 \mathrm{wt} \%$ 까지 첨 가하였을 경우의 비중은 $0.95 \mathrm{~g} / \mathrm{cm}^{3}$ 까지 증가 하였다. $\mathrm{CaCO}_{3}$ 첨가에 따른 열전도율 변화에서 $\mathrm{CaCO}_{3}$ 를 첨가하 지 않았을 때의 열전도율은 $0.028 \mathrm{kcal} / \mathrm{mh}$ 로 나타났으나 $\mathrm{CaCO}_{3}$ 의 첨가량의 증가할수록 열전도율은 높아져 $65 \mathrm{wt} \%$ $\mathrm{CaCO}_{3}$ 를 첨가하였을 경우 $0.039 \mathrm{kcal} / \mathrm{mh}$ 로 나타나고 있다. 즉 $\mathrm{CaCO}_{3}$ 의 첨가율이 증가를 하면 난연 성능 확보에는 도움이 될 수 있을 것으로 기대되나 열전도도는 조금 높 아지는 현상을 보였다.

Fig. 10 에 $\mathrm{CaCO}_{3}$ 첨가량에 따른 SEM 사진을 나타내었 다. $\mathrm{CaCO}_{3}$ 의 첨가량이 증가를 할수록 기공 크기가 작아
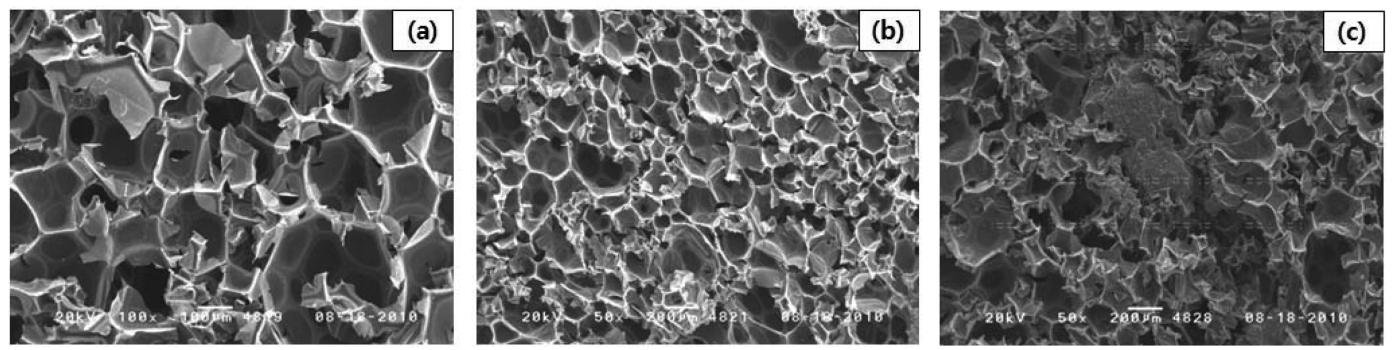

Fig. 10. SEM photographs of foamed body with addition amount of $\mathrm{CaCO}_{3}$ (a) $30 \%$, (b) $50 \%$, and (c) $65 \%$. 
지고 있으며 첨가량이 $65 \%$ 로 증대하였을 경우 기공의 일 부가 붕괴되어 있고 $\mathrm{CaCO}_{3}$ 입자도 응집되어 있는 현상 을 볼 수 있었다.

\section{4. 결 론}

유기단열소재인 우레탄 소재에 무기질 충진재로 $\mathrm{CaCO}_{3}$ 를 복합화 하여 발포시킬 때의 각종 발포조건에 따른 유무기 복합단열소재의 특성을 평가 수행한 결과 다음과 같 은 결론을 얻었다.

1) 폴리올과 이소시아네이트의 비에 따른 특성분석 결 과 폴리올과 이소시아네이트의 무게비가 $1: 1.2$ 일 경우 발포특성이 양호하였으며 비중이 가장 낮았다.

2) 폴리올과 이소시아네이트를 각각 $5 \mathrm{~g}$ 과 $6 \mathrm{~g}$ 으로 고정 시키고 계면활성제 촉매 발포제(물)를 변수로하여 비중과 열전도율을 측정한 결과 측정 결과 계면활성제 $0.1 \mathrm{~g}$, 촉 매 $0.1 \mathrm{~g}$, 발포제(물) $0.4 \mathrm{~g}$ 첨가하였을 때 가장 좋은 결과 를 얻었다.

3) 계면활성제, 촉매, 발포제(물) 첨가에 따른 미세조직 관찰결과 계면활성제, 촉매를 첨가하지 않았을 때는 일정 한 기공구조를 가지지 않았고, 발포가 잘 이루어지지 않 아 열전도율, 비중 또한 높은 값을 보였다. 특히 물을 첨 가하지 않았을 때에는 발포가 거의 이루어지지 않아 기 공형성이 어려웠다.

4) $\mathrm{CaCO}_{3}$ 의 첨가량이 증가할수록 발포체의 기공크기가 줄어들고 있으며 무기분체의 응집현상이 일어나 비중과 열전도율이 증가 하였다.

\section{REFERENCES}

1. V. Pruskus, J. Bivainis, R. Gudauskas, and V. Plakys, "Passive House Model for Quantitative and Qualitative Analyses and Its Intelligent System," Energy Buildings, 50 7-18 (2012).

2. J. Mlakar and J. Štrancar, "Overheating in Residential Passive House: Solution Strategies Revealed and Confirmed Through Data Analysis and Simulations," Energy Buildings, 43 1443-51 (2011).
3. V. Badescu and M. D. Staicovici, "Renewable Energy for Passive House Heating: Model of the Active Solar Heating System," Energy Buildings, 38 129-41 (2006).

4. M. Jerman, R. Cerný, "Effect of Moisture Content on Heat and Moisture Transport and Storage Properties of Thermal Insulation Materials," Energy Buildings, 53 39-46 (2012).

5. M. Alam, H. Singh, and M. C. Limbachiya, "Vacuum Insulation Panels (VIPs) for Building Construction Industry-A Review of the Contemporary Developments and Future Directions," Appl. Energy, 88 3592-602 (2011).

6. J. -S. Kwon, C. H. Jang, H. Jung, and T. -H. Song, "Effective Thermal Conductivity of Various Filling Materials for Vacuum Insulation Panels," Inter. J. Heat Mass Trans., 52 552532 (2009).

7. A. A. Stec and T. R. Hull, "Assessment of the Fire Toxicity of Building Insulation Materials," Energy Buildings, 43 498506 (2012).

8. H. -H. Liang, M. -C. Ho, "Toxicity Characteristics of Commercially Manufactured Insulation Materials for Building Applications in Taiwan," Construction Building Mater, 21 1254-61 (2007).

9. A.M. Papadopoulos, "State of the Art in Thermal Insulation Materials and Aims for Future Developments," Energy Buildings, 37 77-86 (2005).

10. Satta Panyakaew and Steve Fotios, "New Thermal Insulation Boards Made from Coconut Husk and Bagasse," Energy Buildings, 43 1732-39 (2011).

11. J. R. Correia, F. A. Branco, and J. G. Ferreira, "The Effect of Different Passive Fire Protection Systems on the flre Reaction Properties of GFRP Pultruded Profiles for Civil Construction," Composites Part A: Appl. Sci. Manufacturing, 41 441-52 (2010).

12. R. Baetens, B. Petter Jelle, and A. Gustavsen, "Aerogel Insulation for Building Applications: A State-of-The-art Review," Energy Buildings, 43 761-69 (2011).

13. V. Vaou and D. Panias, "Thermal Insulating Foamy Geopolymers from Perlite," Minerals Eng., 23 1146-51 (2010).

14. F. Laoutid, L. Bonnaud, M. Alexandre, J.-M. Lopez-Cuesta, and Ph. Dubois, "New Prospects in Flame Retardant Polymer Materials: From Fundamentals to Nanocomposites," Mater. Sci. Eng.: R. Reports, 63 100-25 (2009). 